\title{
Low FasL levels promote proliferation of human bone marrow-derived mesenchymal stem cells, higher levels inhibit their differentiation into adipocytes
}

\author{
MR Rippo*, ${ }^{*}$, L Babini ${ }^{1}$, F Prattichizzo ${ }^{1}$, L Graciotti ${ }^{1}$, G Fulgenzi ${ }^{1,2}$, F Tomassoni Ardori ${ }^{2}$, F Olivieri ${ }^{1,3}$, G Borghetti $^{1}$, S Cinti ${ }^{4}$, A Poloni ${ }^{5}$, \\ F Fazioli ${ }^{1}$ and AD Procopio ${ }^{1,3}$
}

Mesenchymal stem cells (MSCs) are multipotent progenitor cells that can differentiate into several cell types. Bone marrow (BM)-MSCs mainly differentiate into osteoblasts or adipocytes. MSC interactions with their microenvironment directly affect their self-renewal/differentiation program. Here, we show for the first time that Fas ligand (FasL), a well-explored proapoptotic cytokine, can promote proliferation of BM-derived MSCs in vitro and inhibits their differentiation into adipocytes. BM-MSCs treated with a low FasL dose $(0.5 \mathrm{ng} / \mathrm{ml})$ proliferated more rapidly than untreated cells without undergoing spontaneous differentiation or apoptosis, whereas higher doses $(25 \mathrm{ng} / \mathrm{ml})$ induced significant though not massive BM-MSC death, with surviving cells maintaining a stem cell phenotype. At the molecular level, $0.5 \mathrm{ng} / \mathrm{ml}$ FasL induced ERK1/2 phosphorylation and survivin upregulation, whereas $25 \mathrm{ng} / \mathrm{ml}$ FasL induced caspase activation. Importantly, $25 \mathrm{ng} / \mathrm{ml}$ FasL reversibly prevented BMMSC differentiation into adipocytes by modulating peroxisome proliferator-activated receptor gamma (PPAR $\gamma$ ) and FABP4/aP2 expression induced by adipogenic medium. All such effects were inhibited by anti-Fas neutralizing antibody. The in vitro data regarding adipogenesis were confirmed using Fas ${ }^{\mathrm{IPr}}$ mutant mice, where higher PPAR $\gamma$ and FABP4/aP2 mRNA and protein levels were documented in whole tibia. These data show for the first time that the FasL/Fas system can have a role in BM-MSC biology via regulation of both proliferation and adipogenesis, and may have clinical relevance because circulating Fas/FasL levels decline with age and several age-related conditions, including osteoporosis, are characterized by adipocyte accumulation in BM. Cell Death and Disease (2013) 4, e594; doi:10.1038/cddis.2013.115; published online 18 April 2013

Subject Category: Immunity

Mesenchymal stem cells (MSCs) are especially numerous in the bone marrow (BM) stroma, where they form a structurally unique niche with hematopoietic stem cells (HSCs). This niche is tightly regulated by local microenvironmental inputs. ${ }^{1}$ However, BM-MSCs are also found at low frequency in most adult connective tissues. $^{2}$

The interactions of BM-MSCs with their microenvironment directly affect their stem cell self-renewal or differentiation program, which includes osteogenesis and adipogenesis. In addition to hematopoietic progenitors and their progeny, several cell types (e.g. fibroblasts, endothelial cells, osteoblasts, osteoclasts, adipocytes, and immune cells) supply factors to BM-MSCs; in turn, BM-MSCs are essential for HSC differentiation, mobilization, and exit from the marrow compartment. $^{3}$

A number of factors have important roles in BM-MSC proliferation and stemness maintenance, including basic fibroblast growth factor (bFGF), ${ }^{4}$ heparin-binding epidermal growth factor-like growth factor (HB-EGF), ${ }^{5}$ and interleukin 6 (IL-6), ${ }^{6}$ whereas factors such as bone morphogenic proteins, insulin, and insulin-like growth factor IGF $1^{7,8}$ induce BM-MSC differentiation into osteoblasts and adipocytes.

Commitment of BM-MSCs to the osteoblast or adipocyte fate occurs through a highly regulated mechanism, where lineage-specific transcription factors are ultimately activated. The master transcriptional regulator of adipogenesis is peroxisome proliferator-activated receptor gamma (PPAR $\gamma$ ). Its transcripts generally increase more than 10-fold within a few days of adipogenic stimulation. Furthermore, PPAR $\gamma$ has a crucial role in the function of fat cell-specific genes during late differentiation. ${ }^{9} \mathrm{~A}$ variety of downstream genes are then induced, which contribute to acquisition of the mature phenotype, including adiponectin and the adipocyte binding protein FABP4/aP2. ${ }^{10,11}$

BM adipogenesis is a physiological process. Marrow fat has a variety of functions, including maintenance of the bone

\footnotetext{
${ }^{1}$ Laboratory of Experimental Pathology, Department of Clinical and Molecular Sciences, Università Politecnica delle Marche, Ancona, Italy; ${ }^{2}$ Neural Development Group, Mouse Cancer Genetics Program, Center for Cancer Research, National Cancer Institute, Frederick, MA, USA; ${ }^{3}$ Center of Clinical Pathology and Innovative Therapies, Italian National Research Center on Aging (INRCA-IRCCS), Ancona, Italy; ${ }^{4}$ Department of Experimental and Clinical Medicine, Obesity Center-United HospitalsUniversity of Ancona, Università Politecnica delle Marche, Ancona, Italy and ${ }^{5}$ Clinic of Hematology, Department of Clinical and Molecular Sciences, Università Politecnica delle Marche, Ancona, Italy

${ }^{*}$ Corresponding author: MR Rippo, Laboratory of Experimental Pathology, Department of Clinical and Molecular Sciences, Università Politecnica delle Marche, Via Tronto 10 60020, Ancona, Italy. Tel: +39 071220 6242, Fax: +39 071220 6240; E-mail: m.r.rippo@ univpm.it

Keywords: bone marrow-derived mesenchymal stem cells; Fas ligand; proliferation; adipogenesis; peroxisome proliferator-activated receptor gamma

Abbreviations: FasL, Fas ligand; BM-MSCs, bone marrow-derived mesenchymal stem cells; HSCs, hematopoietic stem cells; bFGF, basic fibroblast growth factor; HB-EGF, epidermal growth factor-like growth factor HB-EGF; IL-6, interleukin 6; IGF1, insulin-like growth factor 1; PPAR $\gamma$, peroxisome proliferator-activated receptor gamma; aP2, adipocyte binding protein; qRT-PCR, quantitative real-time PCR

Received 03.8.12; revised 24.1.13; accepted 20.2.13; Edited by Y Shi
} 
microenvironment and of bone energy. ${ }^{12}$ However, excessive or poor marrow fat is a feature of several pathological conditions, including multiple myeloma, anorexia nervosa, osteoarthritis, osteoporosis related to advanced age, and HIV-associated lipodystrophy. ${ }^{3,13,14}$ During aging, B-MSCs lose some of their differentiation potential. It has been proposed that MSCs are by default programmed to differentiate into adipocytes, but that the optimal osteoblastogenesis conditions found in young bone are impaired by the aging process, resulting in excessive adipogenesis. ${ }^{15}$

A factor for which a role in bone differentiation and homeostasis is emerging is Fas ligand (FasL). Although FasL was initially described as a T-cell-associated protein capable of inducing apoptosis by binding to its receptor Fas, ${ }^{16}$ a pleiotropic role in other cell populations has also been described over the last few years. The Fas/FasL system has a number of actions that include induction of proapoptotic signals in normal cells, immune system homeostasis regulation, and enhancement of the resistance of most cancer cells to its own proapoptotic signals. ${ }^{17}$ Fas engagement in resting T lymphocytes transduces inhibitory or costimulatory signals in a FasL dose-dependent manner, ${ }^{18}$ and in hematopoietic progenitors FasL receptor transduces dual apoptotic and trophic signals via caspase-dependent and -independent molecular mechanisms, respectively. ${ }^{19}$ There are two physiologically active forms of FasL, membrane-bound (mFasL) and soluble (sFasL): mFasL is essential for Fas-induced killing of target cells and activation-induced cell death, whereas sFasL induces non-apoptotic signals, possibly including stimulation of cell proliferation, survival, or inflammation within an elevated cytokine milieu. ${ }^{20}$ Therefore, $\mathrm{mFasL}$ is essential for cytotoxic activity and protects against autoimmunity and cancer, whereas excess sFasL appears to promote autoimmunity, tumorigenesis and cancer progression through non-apoptotic actions. ${ }^{20,21}$ Several conditions have been associated to and could be mediated by increased circulating sFasL levels, including AIDS, ${ }^{22,23}$ acute myocardial infarction, ${ }^{24}$ and Graves' hyperthyroidism. ${ }^{25}$ Besides its death-promoting activity, FasL has been implicated in reverse signaling and might thus also have a role in T-cell development and selection and in TCR signaling modulation, functioning as a typical costimulator. ${ }^{26}$ Finally, the FasL intracellular domain can be released into cytosol, enter the nucleus and directly modulate transcriptional activity. ${ }^{27}$

Fas and FasL are expressed in freshly isolated BM-MSCs, both human and mouse. ${ }^{28,29}$ However, cell death induction does not seem to be the Fas/FasL system's main role in bone homeostasis. Fetal BM-MSCs have been shown to have functional extrinsic apoptotic pathways, ${ }^{30,31}$ whereas adult BM-MSCs are resistant to Fas-mediated apoptosis. ${ }^{29}$ Furthermore, FasL has a limited role in osteoblast and osteoclast apoptosis, but inhibits osteoblast differentiation in mice. ${ }^{28}$ During osteoblastogenesis FasL expression rapidly decreases and remains low until the end of the differentiation process, whereas Fas levels rise. ${ }^{28,32}$ Even more importantly, absence of Fas and FasL stimulates osteoblast differentiation, as both Fas - / - and gld mice have greater osteoblastogenic potential than control mice. ${ }^{28}$ These findings suggest that the Fas/FasL system has a role in controlling the BM-MSC differentiation program.
We investigated the effect of FasL on BM-MSC apoptosis, proliferation, and differentiation into adipocytes to clarify the role of the Fas/FasL system in BM-MSC biology. Here we show for the first time that FasL exerts a pleiotropic action on BM-MSCs depending on its concentration: low doses induce proliferation, whereas higher doses have a slight but significant apoptotic effect and, more importantly, inhibit adipogenesis; all such effects are exerted without affecting BM-MSC stemness, irrespective of dosage.

Our findings show a FasL-dependent regulation of BMMSC biology and adipogenesis, and suggest a role for Fas $L$ in conditions involving altered BM adipogenesis, such as osteoporosis in the elderly.

\section{Results}

FasL has a dose-dependent dual effect on BM-MSCs. The effect of different doses of human recombinant FasL (from 0.1 to $5 \mathrm{ng} / \mathrm{ml}$ ) on proliferation of batch no. 1 BM-MSCs was examined on days 2, 4, and 6 of culture (Figure 1a). Cell counts indicated that all doses except the highest enhanced cell proliferation, $0.5 \mathrm{ng} / \mathrm{ml}$ having the strongest effect $(30 \%$ increase versus control on day 6). The proliferative effect was not donor-related, as $0.5 \mathrm{ng} / \mathrm{ml}$ FasL also increased cell number in batches no. 2 and no. 3 (Supplementary data, Figure 1). The effect of this dose was validated by BrdU assay data on day 6 and was neutralized by anti-Fas antibody (Figure 1b). Cell number comparisons on day 6 showed nonsignificant differences among cultures treated with $0.5 \mathrm{ng} / \mathrm{ml}$ FasL and those treated with trophic factors FGF $(5 \mathrm{ng} / \mathrm{ml})$ and EGF $(50 \mathrm{ng} / \mathrm{ml})$ (Figure 1c). To establish whether the proliferative effect of $0.5 \mathrm{ng} / \mathrm{ml}$ was transient or persistent, cell numbers were also assayed on day 14; the effect was found to persist at least 14 days into treatment (Figure 1d).

The effect of higher FasL doses $(25 \mathrm{ng} / \mathrm{ml})$ on BM-MSCs (batch no. 1) was also examined on days 1, 2, 4, and 6. FasL reduced cell number (data not shown) and had a significant proapoptotic effect on day 1 (22\% of apoptotic cells) that subsequently decreased (Figure 2a). As $5 \mathrm{ng} / \mathrm{ml}$ FasL reduced BM-MSC proliferation (Figure 1a), the proapoptotic effect of doses $<25 \mathrm{ng} / \mathrm{ml}$ FasL (from 0.5 to $2.5 \mathrm{ng} / \mathrm{ml}$ ) was also examined and compared with the effect of $25 \mathrm{ng} / \mathrm{ml}$ FasL. As expected, low doses did not exert a significant proapoptotic effect, whereas $5 \mathrm{ng} / \mathrm{ml}$ FasL had a weak proapoptotic effect (7\% of apoptotic cells). To compare these data with those obtained by other groups, ${ }^{29}$ Fas triggering was also induced with a low $(50 \mathrm{ng} / \mathrm{ml})$ or a high dose $(1000 \mathrm{ng} / \mathrm{ml})$ of the agonistic anti-Fas antibody (Figure $2 b$ ).

At the molecular level, Fas-induced proapoptotic signaling was assayed on day 1 of culture by examining processing of pro-caspase 8 and 3 that indicates their activation. Figure $2 \mathrm{c}$ shows that $0.5 \mathrm{ng} / \mathrm{ml}$ FasL had a weak effect, whereas $25 \mathrm{ng} / \mathrm{ml} \mathrm{FasL}$ induced a decline in pro-caspase 8 and 3 that was inhibited by the pan caspase inhibitor zVAD. However, as fragments of active caspase 3 were not detectable in any experiment on day 1 of treatment (Supplementary Figure 2b), its cleavage was assayed (and found) at shorter times (4, 8, and $12 \mathrm{~h}$ ) (Figure 2d).

Therefore, the biological effect of FasL on BM-MSC growth and apoptosis is dose-dependent: low doses $(0.5 \mathrm{ng} / \mathrm{ml})$ 

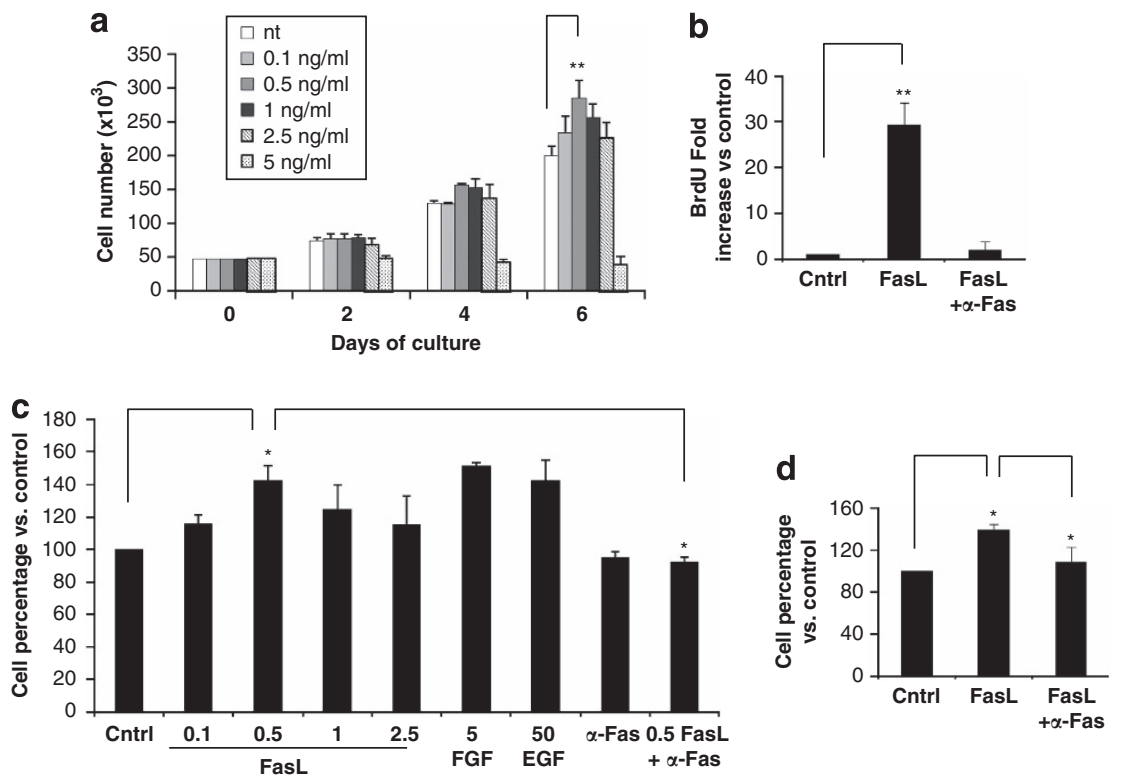

Figure 1 FasL-induced BM-MSC proliferation. (a) BM-MSCs derived from batch no. 1 were treated with FasL doses ranging from 0.1 to $5 \mathrm{ng} / \mathrm{ml}$. Cell growth was assayed by counting total cell number on days 2, 4, and 6; $0.5 \mathrm{ng} / \mathrm{ml}$ FasL had the strongest pro-proliferative effect (mean of four experiments shown). (b) The BrdU assay was performed on the same sample (no. 1) on day 6 of culture with or without $0.5 \mathrm{ng} / \mathrm{ml} \mathrm{FasL.} \mathrm{Results} \mathrm{are} \mathrm{expressed} \mathrm{as} \mathrm{BrdU} \mathrm{fold} \mathrm{change} \mathrm{compared} \mathrm{with} \mathrm{untreated} \mathrm{cells} \mathrm{(cntrl).}$ $\mathrm{N}=3$. (c) FasL-induced proliferation (expressed as cell \% versus cntrl) on day 6 was compared with FGF- $(5 \mathrm{ng} / \mathrm{ml})$, and EGF- ( $50 \mathrm{ng} / \mathrm{ml})$-induced proliferation; proliferation was assayed as in (a). $N=4$. (d) Long-term FasL-induced proliferation was analyzed as in (a) by comparing untreated (cntrl) and FasL ( $0.5 \mathrm{ng} / \mathrm{ml})$-treated cells. ZB4 anti-Fas antibody was used (FasL $+\alpha$-Fas) to test the specificity of the FasL-mediated effect on day $14 .{ }^{* *} P<0.01,{ }^{*} P<0.05 N=3$, (b-d): Student's $t$-test. Data are expressed as mean \pm S.D. Where indicated, ZB4 antibody $(\alpha-F a s)(500 \mathrm{ng} / \mathrm{ml})$ was added to the culture $20 \mathrm{~min}$ before treatments to test the specificity of the FasL-mediated effects

a

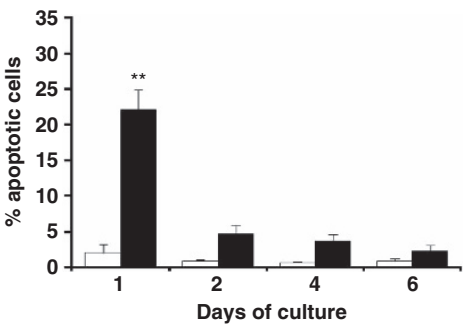

C

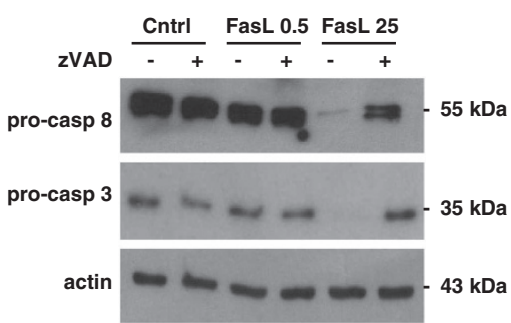



d

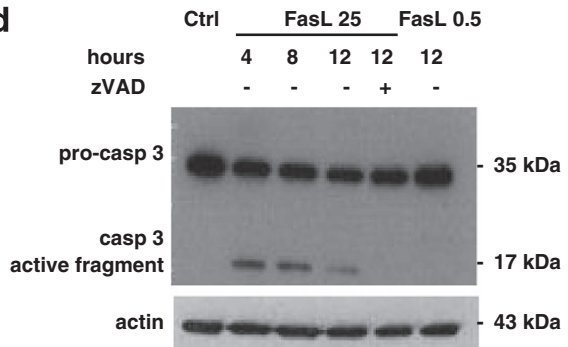

Figure 2 FasL induced BM-MSC apoptosis. (a) BM-MSCs from batch no. 1 were treated with $25 \mathrm{ng} / \mathrm{ml} \mathrm{FasL} \mathrm{(black} \mathrm{bars)} \mathrm{or} \mathrm{left} \mathrm{untreated} \mathrm{(white} \mathrm{bars);} \mathrm{the} \mathrm{percentage} \mathrm{of}$ apoptotic cells was evaluated by Hoechst staining and fluorescence microscopy analysis on days 1,2, 4, and 6. Data are expressed as mean \pm S.D. (b) BM-MSCs from batch no. 1 were treated with different FasL doses ranging from 0.5 to $25 \mathrm{ng} / \mathrm{ml}$ (black bars) or with 50 and $1000 \mathrm{ng} / \mathrm{ml}$ of anti-Fas human activating clone $\mathrm{CH} 11$ (white bars). The percentage of apoptotic cells was evaluated on day 1 as in (a). Data are expressed as mean \pm S.D. ${ }^{* \star} P<0.01$. (c) FasL-induced caspase 8 and 3 activation was assayed by western blotting of their pro-enzymes, pro-casp-8, and pro-casp-3 (mouse anti-caspase 3 , no. 9668) on day 1 of treatment. The pan caspase inhibitor zVAD (20 $\mu \mathrm{m}$ ) was added $20 \mathrm{~min}$ before treatment to control the specificity of activation. $N=3$. One representative western blot is shown here, the other caspase 3 blots are reported in Supplementary

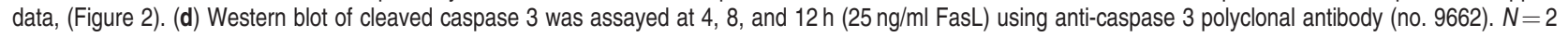

promote cell proliferation and do not induce apoptosis, whereas high doses $(25 \mathrm{ng} / \mathrm{ml})$ induce apoptosis of a limited proportion of cells.
FasL does not affect the BM-MSC phenotype. The expression of a number of MSC markers was examined in BM-MSCs treated with $0.5 \mathrm{ng} / \mathrm{ml}$ or $25 \mathrm{ng} / \mathrm{ml}$ FasL for 1 day 
a
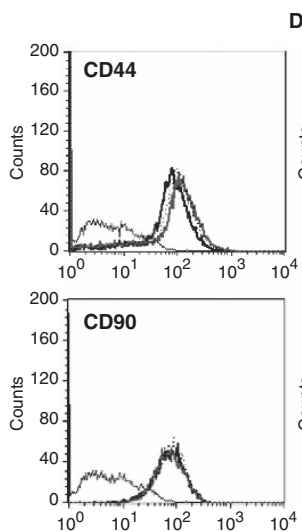

Day 1
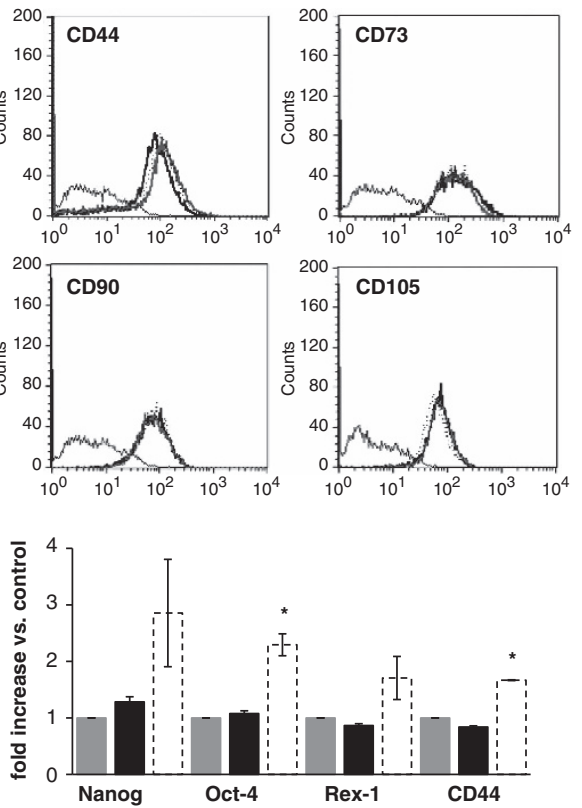

b
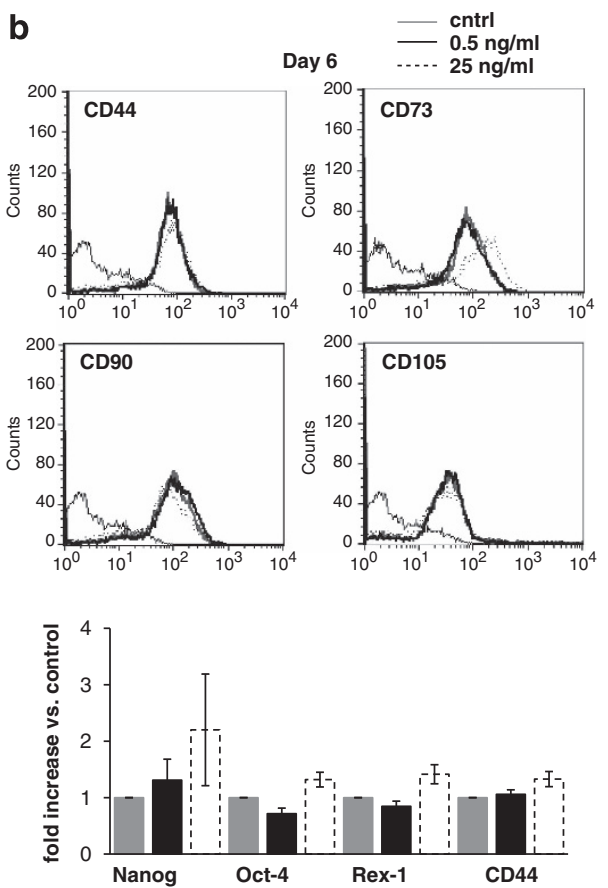

Figure 3 FasL did not modulate BM-MSC markers. BM-MSC were left untreated (cntrl) or treated with $0.5 \mathrm{ng} / \mathrm{ml}$ or $25 \mathrm{ng} / \mathrm{ml}$ FasL for 1 day (a) or 6 days (b). Cntrl BMMSCs (gray line) or BM-MSCs treated with $0.5 \mathrm{ng} / \mathrm{ml}$ (black line) or $25 \mathrm{ng} / \mathrm{ml}$ FasL (dotted line) were stained with antibodies against CD105, CD73, CD44, and CD90 for cytofluorimetric analysis of membrane expression. Mean fluorescence was compared with FITC or PE isotypes (upper panels). $N=3$. Nanog, Oct-4, Rex-1, and CD44 mRNA expression were analyzed by qRT-PCR in untreated (control) BM-MSCs (gray bars) and in BM-MSCs treated with $0.5 \mathrm{ng} / \mathrm{ml} \mathrm{FasL} \mathrm{(black} \mathrm{bars),} \mathrm{or} 25 \mathrm{ng} / \mathrm{ml}$ FasL (hatched bars), and the level expressed as fold increase versus control $\left({ }^{*} P<0.05\right)$. $N=3$. Data are expressed as mean \pm S.E.

(Figure $3 a$ ) and 6 days (Figure $3 b$ ), to evaluate the phenotype of proliferating and survivor cells. CD105, CD73, $\mathrm{CD} 44$, and $\mathrm{CD} 90^{33}$ were all expressed in cells treated with 0.5 and in those treated with $25 \mathrm{ng} / \mathrm{ml}$ FasL; their levels were comparable to those of untreated cells at both time points ( $a$ and $b$, upper panels) except for CD73, which on day 6 was slightly increased in cells treated with $25 \mathrm{ng} / \mathrm{ml}$ FasL. Quantitative real-time PCR (qRT-PCR) analysis of transcription factors Rex- 1 , Nanog, and Oct- 4 and of CD44 mRNA documented the expression of these four molecules in untreated cells both on day 1 and on day 6 (data not shown). Interestingly, their mRNA levels, reported as fold increase versus untreated cells (control), were unchanged at both time points with $0.5 \mathrm{ng} / \mathrm{ml}$ ( $\mathrm{a}$ and $\mathrm{b}$, lower panel), but were slightly increased by $25 \mathrm{ng} / \mathrm{ml}$ FasL on day 1 (a, lower panel). These data demonstrate that FasL does not reduce BM-MSC stemness.

FasL induces ERK/1-2 phosphorylation and survivin expression. As in conditions favoring proliferation FasL induces ERK1/2 activation, ${ }^{21,34}$ and BM-MSCs maintain a stem cell phenotype through ERK1/2-dependent mechanisms, ${ }^{6}$ we explored ERK $1 / 2$ activation in BM-MSCs treated with $0.5 \mathrm{ng} / \mathrm{ml}$ FasL. As documented in Figure $4 \mathrm{a}$, FasL induced ERK phosphorylation with two peaks at 5 and $30 \mathrm{~min}$, respectively. Furthermore, as survivin is an important factor for cell death resistance and in particular modulates HSC cycle and proliferation, ${ }^{35}$ its expression was determined in proliferating FasL-treated BM-MSCs at different times. Survivin protein expression was lower than in untreated cells on day 2
(Figure 4b), in line with Rodrigues et al., ${ }^{31}$ but it was greater on days 4 and 6 . These data lend support to the observation that FasL promotes BM-MSC proliferation (Figure 1).

FasL inhibits BM-MSC differentiation into adipocytes. It has been reported that FasL inhibits murine osteoblastogen$\mathrm{esis}^{28}$, and we found that BM-MSCs survived FasL treatment and retained their stemness characteristics (Figure 3). However, as little information is available on adipogenesis, we assessed the role of FasL in inhibiting BM-MSC differentiation into adipocytes. BM-MSCs were cultured for 14 days in adipogenic medium (AD) alone or supplemented with 0.5 or $25 \mathrm{ng} / \mathrm{ml}$ FasL. Cells were then stained with Oil Red O to count adipocytes, and with methylene blue to count total cell number. While $0.5 \mathrm{ng} / \mathrm{ml}$ FasL had very little effect on adipogenesis inhibition (data not shown), $25 \mathrm{ng} / \mathrm{ml}$ FasL inhibited lipid droplet accumulation (Figure 5a). The percentage of differentiated cells out of total cell number in each culture condition was compared with the percentage of differentiated cells found in cultures grown in $A D$ alone, considered $=100 \%$. The results showed that in FasL-supplemented AD adipogenesis was inhibited by about $50 \%$ (Figure $5 b$ ). For this to happen FasL had to be present throughout the culture time. Importantly, these data are corroborated by the finding that FasL also inhibited AD-induced expression of PPAR $\gamma$, adiponectin, and FABP4/aP2 differentiation genes, as documented by qRTPCR (Figure 5c). All such effects were specific because they were neutralized by ZB4 anti-Fas antibody.

To exclude that adipogenesis impairment in FasL-supplemented cells was due to the proapoptotic action of FasL or to a 
a
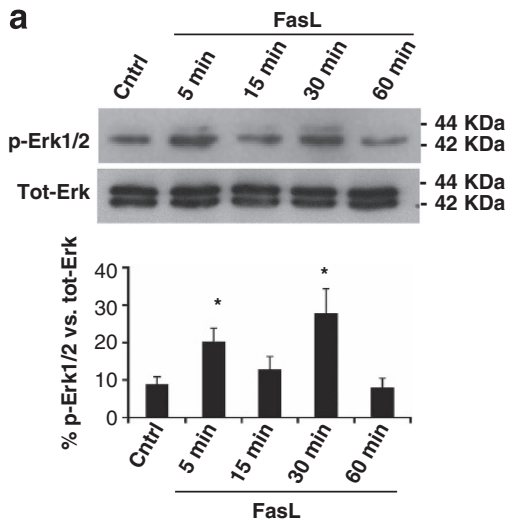

b
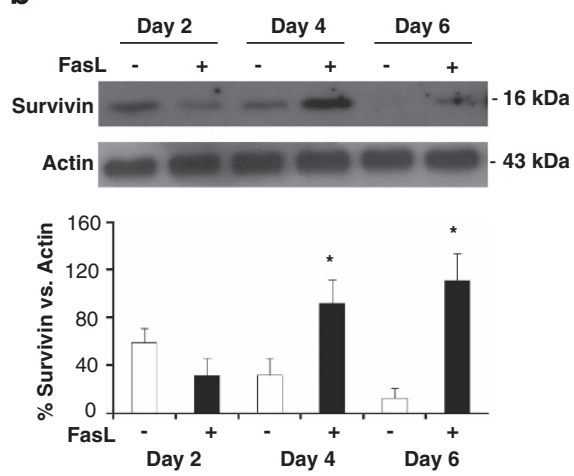

Figure 4 FasL induced ERK1/2 phosphorylation and survivin upregulation in BM-MSCs. (a) BM-MSCs (batch no. 1) were treated with $0.5 \mathrm{ng} / \mathrm{ml}$ FasL for $5,15,30$, or $60 \mathrm{~min}$ and cell lysates immunoblotted with anti-phospho-ERK1/2 (p-ERK1/2) and anti-total ERK (tot-Erk; upper panel). Protein levels were evaluated by densitometric analysis and the amount of $p$-ERK was expressed as a percentage of tot-ERK (lower panel). $N=3$. (b) Survivin expression in BM-MSCs, untreated (white bars) or treated with $0.5 \mathrm{ng} / \mathrm{ml} \mathrm{FasL}$ (black bars), was analyzed on day 2, 4, and 6 of culture by western blotting (upper panel), quantified by densitometric analysis, and expressed as percentage of actin level (lower panel) $N=3$. Data are expressed as mean \pm S.D.

donor effect, BM-MSCs from three different donors (batches no. 1, 2, and 3) were first analyzed for their adipogenic potential. All three batches were found to exhibit a comparable proportion of adipocytes after 14 days in AD medium (Supplementary Figure 3a). They were subsequently exposed to $25 \mathrm{ng} / \mathrm{ml}$ FasL in normal medium ( $\alpha$-MEM) for 2 days, to induce apoptosis of all susceptible cells; $\alpha$-MEM was then replaced with $A D$ medium or with $A D$ medium supplemented with $25 \mathrm{ng} / \mathrm{ml}$ FasL, to induce adipogenesis of surviving cells. At the end of the differentiation period (day 16), cells were stained with Oil Red O to count adipocytes; methylene blue to establish total cell number (Figure $6 \mathrm{a}$ and Supplementary Figure 3b); and Hoechst to assess apoptosis (Figure 6a). Despite a degree of interindividual variability, total cell number did not differ significantly between FasL-supplemented and unsupplemented cultures (AD 29.3/field $\pm 7.7 ;$ AD + FasL 24.8/field \pm 5.6 ; 20 fields assayed), whereas adipocytes were considerably reduced in all FasL-supplemented cultures. This could not be due to apoptosis, because few cells dosed with $25 \mathrm{ng} / \mathrm{ml}$ FasL were apoptotic on day 2 (Figure 2a), and floating apoptotic cells had been removed with the medium. Furthermore, apoptotic cells were not detected on day 16 (Figure 6a, right panel). The percentage of differentiated cells out of the total cell number in each culture condition was then computed and compared with the proportion of differentiated cells found in AD cultures $(=100 \%)$. Figure $6 \mathrm{~b}$ shows that FasL inhibition exceeded $60 \%$ and that the effect was specific because it was neutralized by ZB4 Fas antibody.

Overall these findings demonstrate that FasL can inhibit adipogenesis in vitro

Fas $^{\text {Ipr }}$ mice show increased levels of adipogenic markers in bone. To validate the in vitro data regarding the role of the Fas/FasL system in adipogenesis, the expression of the adipogenic factor PPAR $\gamma$ and of the adipose tissue marker FABP4/aP2 was analyzed in whole tibia from 10-week-old B6.MRL-Fas ${ }^{\mathrm{Ipr}} / \mathrm{J}$ mice and C57BL/6J control mice (5/group) (Figure 7). The mRNA levels of PPAR $\gamma$, FABP4 and RUNX2 (used as a bone marker) were determined by qRT-PCR. Average mRNA fold changes showed upregulation of both
PPAR $\gamma$ and FABP4/aP2 in Fas ${ }^{\mathrm{lpr}}$ mice but, more importantly, also documented a greater protein expression compared with control animals (Figure 7c). The average densitometric values of PPAR $\gamma$ and FABP4 bands showed a significant increase of PPAR $\gamma$ and FABP4 in Fas ${ }^{\text {Ipr }}$ mice (Figure 7d), suggesting an important role for the Fas/FasL system in bone adipogenesis.

FasL does not affect stem cell potential. As FasL treatment partially inhibited BM-MSC differentiation, we investigated whether treated BM-MSCs retained their stemness. To assay their potential to differentiate into adipocytes, cells were cultured for 3 weeks in three different conditions: $A D$ for the whole period (AD cultures); AD supplemented for the whole period with $25 \mathrm{ng} / \mathrm{ml}$ FasL (AD/FasL cultures), which inhibited adipogenesis (Figure 5); and AD/FasL for the first 2 weeks, and then $A D$ without FasL in the final week (AD/FasL/-FasL cultures). Lipid droplet accumulation (Figure 8a) and PPAR $\gamma$, Rex-1, and CD44 mRNA (Figure $8 b$ ) were explored by Oil Red $O$ staining and qRT$\mathrm{PCR}$, respectively. AD/FasL/-FasL cultures showed an increased number of cells containing lipid droplets and PPAR $\gamma$ upregulation, whereas the stem transcription factor Rex-1 and CD44 were downregulated compared with AD/FasL cultures. All mRNAs in AD/FasL/-FasL cells showed levels comparable to those measured in AD cultures, suggesting that FasL does not affect their potential to differentiate.

\section{Discussion}

This study indicates that FasL exerts a pleiotropic effect on BM-MSCs. Our data document for the first time that FasL can induce in vitro both BM-MSC proliferation and apoptosis depending on its concentration and, more importantly, that it inhibits their differentiation into adipocytes. In particular, treatment with low-dose $(0.5 \mathrm{ng} / \mathrm{ml})$ FasL for 6 days increased BM-MSC number by about $30 \%$ compared with untreated cultures, in a similar way to EGF and FGF (Figure 1); this effect was still noted in long-term cultures (Figure 1d). 
a
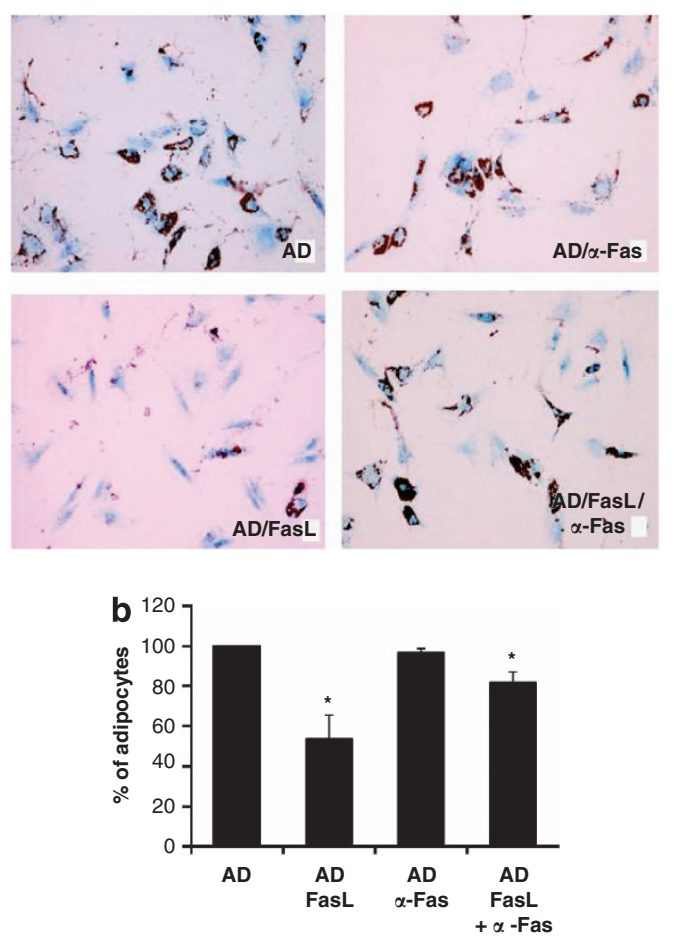
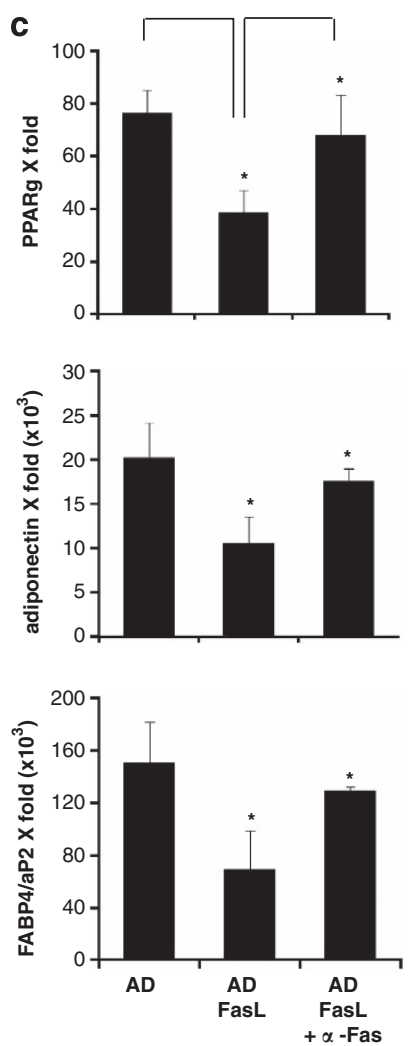

Figure 5 FasL inhibited BM-MSC differentiation induced by adipogenic medium. BM-MSCs from batch no. 1 were cultured for 14 days in adipogenic medium alone (AD), in AD plus ZB4 anti-Fas antibody ( $500 \mathrm{ng} / \mathrm{ml}$ ) (AD $+\alpha$-Fas), AD plus $25 \mathrm{ng} / \mathrm{ml}$ FasL (AD + FasL), or AD plus FasL and $\alpha$-Fas (AD + FasL $+\alpha$-Fas). (a) Samples were stained with methylene blue to reveal all cells and with Oil Red $O$ to detect adipocytes ( $\times 10$ magnification). (b) Total cell number and adipocytes were counted in at least 20 fields per experimental condition by light microscopy; the percentage of differentiated cells out of the total number of cells in each condition was compared with adipocytes found in $A D$ cultures, considered $=100 \% . N=3$. Data are expressed as mean \pm S.D. (c) PPAR $\gamma$, adiponectin, and FABP4/aP2 mRNA levels in cells cultured for 14 days in $A D$, in $\mathrm{AD}+\mathrm{FasL}$ or $\mathrm{AD}+$ FasL $+\alpha$-Fas, mRNA expressed as $\mathrm{X}$-fold $\left(2^{-\Delta \Delta C t}\right)$ versus untreated control (cells cultured in maintaining medium $\alpha$-MEM). Data are expressed as mean \pm S.D. ${ }^{*} P<0.05, N=3$

Two important proliferation markers, ERK and survivin, were sought and found in this system. Rapid activation of ERK1/2 phosphorylation was demonstrated within minutes of treatment (Figure 4a). ERK1/2 activation is induced by EGF combined with bFGF ${ }^{36}$ or by IL-6; it is a key pathway through, which IL-6 regulates both proliferation and inhibition of MSC differentiation. ${ }^{6}$ Survivin is not only an antiapoptotic factor, but also a critical regulator of cell division, and its expression peaks at mitosis. Its conditional deletion results in mitotic defects, cell death and tissue involution. ${ }^{37-39}$ As shown in Figure $4 \mathrm{~b}$ survivin expression correlated with FasL-induced proliferation: it was downregulated while FasL-promoted BM-MSC proliferation was still limited (day 2), but upregulated when cells proliferated more rapidly (days 4 and 6) (Figure 1). Interestingly, $0.5 \mathrm{ng} / \mathrm{ml}$ is a concentration similar to the one found in the sera of young normal subjects ${ }^{40}$ (authors' unpublished observations). Therefore, these data suggest a possible physiological role for FasL in promoting BM-MSC proliferation.

In contrast, higher doses $(25 \mathrm{ng} / \mathrm{ml})$ had a slight but significant proapoptotic effect involving survival of about $75 \%$ of the population (Figure 2). These data are consistent and do not contrast with previous findings. Rodrigues et al. ${ }^{31}$ showed that FasL kills human BM-MSCs through ROS production, BAD activation, and survivin downregulation.
They used higher FasL doses $(100 \mathrm{ng} / \mathrm{ml})$, as their study addressed the death mechanisms of transplanted BM-MSCs in injured tissues, which are characterized by high levels of pro-inflammatory cytokines, including FasL. Kennea et al. ${ }^{30}$ found that, 3 days into culture, $25 \mathrm{ng} / \mathrm{ml}$ FasL induced apoptosis of about $20 \%$ of human fetal MSCs and that $100 \mathrm{ng} / \mathrm{ml}$ FasL induced apoptosis in more than half the population. Similarly, Mazar et al. ${ }^{29}$ documented both Fas and FasL expression by primary BM-MSCs, concluding that they are resistant to Fas-induced apoptosis. The agonistic anti-Fas antibody used in their experiments, used at concentrations ranging from 10 to $100 \mathrm{ng} / \mathrm{ml}$ for $18 \mathrm{~h}$, gave a percentage of apoptotic cells similar to the one shown in our Figure $2 .{ }^{29}$ The additional findings provided by our study are similar expression levels of the stem cell markers in the non-apoptotic population treated with $0.5 \mathrm{ng} / \mathrm{ml} \mathrm{FasL}$, and their increment in the survivor population treated with $25 \mathrm{ng} / \mathrm{ml}$, exclusively on day 1 (Figure 3). One possible explanation for the latter finding is that the proapoptotic dose of $25 \mathrm{ng} / \mathrm{ml}$ FasL (Figure 2) killed those cells exhibiting a higher Fas expression (committed cells, as Fas expression increases during BM-MSC differentiation ${ }^{28,32}$ ), thus selecting for a population with enhanced stem cell properties (Figure 3 ).

These data suggested to us that induction of BM-MSC apoptosis was possibly not the main function of FasL-induced 
signaling. Indeed, our experimental work documented that proapoptotic doses of FasL reversibly inhibited BM-MSC adipogenesis. Adipogenesis inhibition expressed in terms of lipid droplet accumulation (Figure 5a) and of PPAR $\gamma$, adiponectin, and FABP4/aP2 mRNA downregulation


Figure 6 Adipogenesis inhibition does not depend on the proapoptotic effect of FasL. BM-MSCs (batch no. 3 represented) were treated with $25 \mathrm{ng} / \mathrm{ml}$ FasL in $\alpha$-MEM for 2 days. On day 2, $\alpha$-MEM was replaced with adipogenic medium (AD); AD supplemented with $25 \mathrm{ng} / \mathrm{ml} \mathrm{FasL} \mathrm{(AD/FasL);} \mathrm{or} \mathrm{AD} \mathrm{supplemented} \mathrm{with} 25 \mathrm{ng} / \mathrm{ml}$ FasL and ZB4 anti-Fas antibody added 20 min before FasL (AD/FasL/ $\alpha$-Fas). All treatments were applied throughout the differentiation period (14 days). (a) Oil Red $\mathrm{O}$ and methylene blue (left panel) and Hoechst (right panel) staining 14 days from induction of adipogenesis (day 16) ( $\times 10$ magnification). (b) Total cell number and adipocytes were counted in at least 20 fields per experimental condition; the percentage of differentiated cells out of the total number of cells in each condition was compared with adipocytes found in $A D$ cultures, considered $=100 \%$. Data are expressed as mean \pm S.D. ${ }^{*} P<0.05, N=3$ (batches no. 1, 2, and 3 )
(Figure 5b) occurred when AD was continuously supplemented with $25 \mathrm{ng} / \mathrm{ml}$ FasL, a concentration that exerted a proapoptotic effect on cells maintained in non-AD for shorter periods (Figure 2a). Furthermore, adipogenesis inhibition was not induced by the proapoptotic effect of FasL, because pre selection of apoptosis-resistant cells did not reduce adipogenesis inhibition, but rather enhanced it (Figure 6). Interestingly, FasL treatment did not abolish the stem cell potential of BM-MSCs, and adipogenesis inhibition was not irreversible, as FasL subtraction restored the adipogenic process (Figure 8). The demonstration of an in vitro inhibitory effect of Fas/FasL on murine BM-MSC osteoblast differentiation by Kovacić et al. ${ }^{28}$ is in line with these data: BM from mice without functional Fas or FasL generates more osteoblast colonies ex vivo than wild-type BM, suggesting a key role for the Fas/ FasL system in osteoblast differentiation. Accordingly, whole tibia of Fas ${ }^{\text {Ipr }}$ mice expressed higher mRNA and protein levels of PPAR $\gamma$ and FABP4/aP2, respectively the master transcription factor of adipogenesis and the principal adipose tissue marker, compared with control mice.

Altogether these data suggest that FasL is involved in maintaining BM-MSC stemness and in controlling differentiation.

An inhibitory effect of FasL on BM-MSC adipogenesis, particularly on lipid droplet accumulation and PPAR $\gamma$, adiponectin and FABP4/aP2 mRNA expression, has never been described before. However, a 1985 study demonstrated that TNF $\alpha$ acts as a polypeptide hormone with pleiotropic effects on cell proliferation and differentiation, and that it is a potent adipogenesis inhibitor. ${ }^{41}$

Our data raise new questions on the involvement of FasL in adipogenesis not only in BM, but in all tissues where adipocytes have a role, be it physiological or pathological. Marrow fat has a variety of functions, including maintenance of the bone microenvironment and of bone energy, ${ }^{12}$ although a

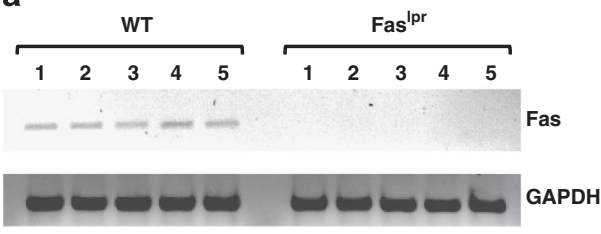

C

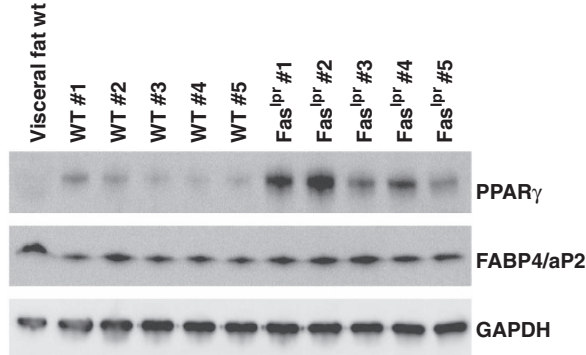



d

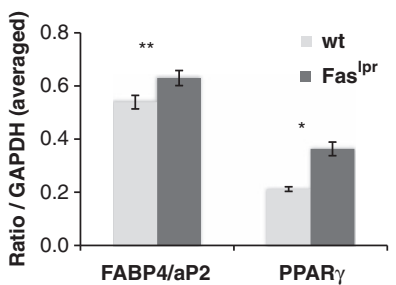

Figure 7 Protein and mRNA expression in Faslpr mice tibias. (a) Genotyping of C57BL/6J (wt) and B6.MRL-Fas/pr/J (Fas ${ }^{\text {lpr }}$ ) mice was performed by RT-PCR: (b) qRTPCR of PPAR $\gamma, F A B P 4$, and RUNX2 mRNA extracted from whole tibia. Data are expressed as mean \pm S.E. (c) Western blot of protein extracted from whole tibia. Membranes were hybridized with PPAR $\gamma$ (adipogenesis marker), FABP4 (adipocyte marker), and GAPDH antibody. Densitometric analysis (d) of protein content showed increased adipose tissue and adipogenesis markers in Fas ${ }^{\text {Ipr }}$ compared with control mice. Two-tailed Student $t$-test. Data are expressed as mean $\pm S$.E. ${ }^{*} P<0.05$ and ${ }^{* *} P<0.001$. Tibia weight: $30.06 \pm 0.07 \mathrm{mg}$ in wt and $30.12 \pm 0.08 \mathrm{mg}$ in Fas ${ }^{\mathrm{lpr}}$ mice 
a

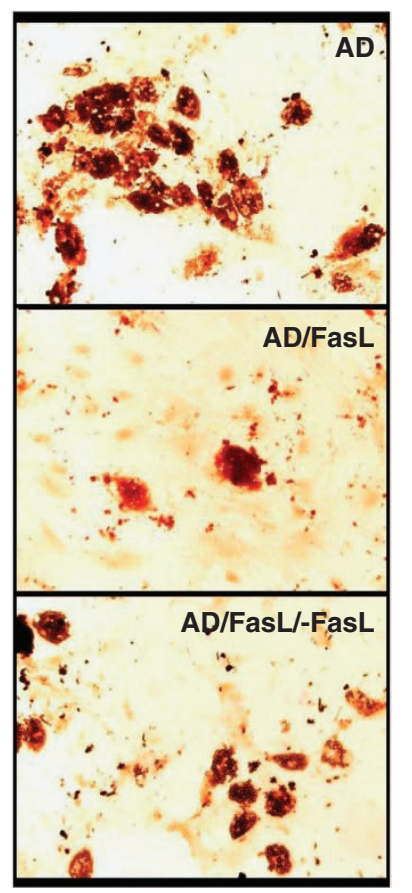

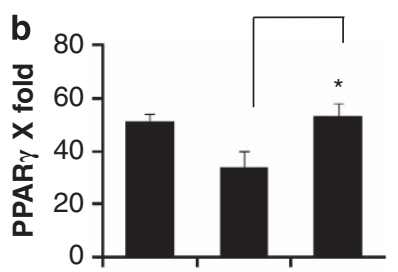
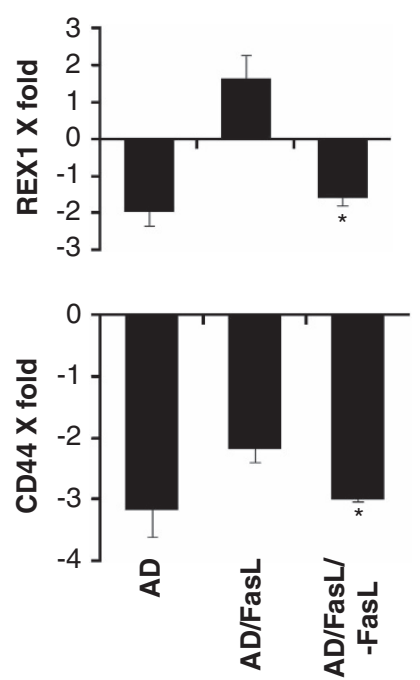

Figure 8 FasL preserved BM-MSC stem cell potential. BM-MSCs were cultured for 3 weeks in $A D$ alone (AD), in AD supplemented with FasL (AD/FasL) or in $A D$ supplemented with FasL $(25 \mathrm{ng} / \mathrm{ml})$ for 2 weeks, and then cultured in $A D$ alone (AD/FasL/-FasL). (a) Oil Red O staining. (b) qRT-PCR of PPAR $\gamma$, Rex-1, and CD44 mRNA. Data were expressed as $\mathrm{X}$-fold $\left(2^{-\Delta \Delta C t}\right)$ versus mRNA of untreated cells. Data are expressed as mean \pm S.D. ${ }^{*} P<0.05$ versus AD/FasL $(N=3)$

it has been shown that adipogenesis impairs hematopoiesis. ${ }^{42}$ Besides having a role in maintaining MSC stemness and in adipogenesis inhibition, FasL could also, conceivably, be involved in regulating hematopoiesis: if this finding were confirmed by further work, FasL would be recognized as a bone homeostasis regulator. Fas and FasL are constitutively expressed in normal adult human BM. Monocytic and, especially, myeloid and CD34 + cells express high FasL levels; ${ }^{43}$ consequently they may all, separately or together, have a role in BM-MSC biology through a closely regulated mechanism. Existing data are insufficient to determine, which FasL form (membrane-bound, soluble, or vesicular) is more relevant to BM-MSC physiology. However, several conditions characterized by altered immune system homeostasis and circulating FasL also show BM adipose tissue changes; for instance sFasL plasma levels in HIV-positive subjects can reach concentrations of $15 \mathrm{ng} / \mathrm{ml}^{23}$ Interestingly, a significantly lower fat fraction has been found in BM of HIV-infected compared with non-HIV-infected men. ${ }^{44}$ On the other hand circulating Fas $L$ can also decrease, for example, during aging, where a progressive decline has been documented in sera ${ }^{40}$ and lymphocytes ${ }^{45}$ of elderly people. Interestingly, BM adipogenesis occurs spontaneously during aging, resulting in primary osteoporosis. ${ }^{15,46}$ Although a correlation between circulating FasL level and BM adipogenesis has never been investigated, it would be interesting to explore the possible connection between in vivo FasL levels and fat loss or gain in

such diseases. This hypothesis is currently being investigated in our lab.

\section{Materials and Methods}

Cell culture. Three different batches of human-derived BM-MSCs, No.1 (\#110877, 22-year-old male), No.2 (\#296577, 45-year-old male), and No.3 (\#1F4019, 29-year-old male), were purchased from Lonza (Allendale, NJ, USA) and maintained in $\alpha$-MEM (Euroclone, 20016, Milano, Italy) supplemented with $10 \%$ fetal bovine serum (FBS) (Lonza) and $1 \%$ penicillin/streptomycin (f) at $37^{\circ} \mathrm{C}$ in a humidified atmosphere containing $5 \% \mathrm{CO}_{2} / 95 \%$ air. Experiments were performed using BM-MSCs up to the fifth passage.

For adipogenic differentiation BM-MSCs were seeded at $5 \times 10^{3} \mathrm{cells} / \mathrm{cm}^{2}$ on six-well plates in AD containing complete $\alpha$-MEM, $2 \mathrm{mM} \mathrm{l-glutamine,} 100 \mathrm{U} / \mathrm{ml}$ penicillin, $100 \mathrm{mg} / \mathrm{ml}$ streptomycin, and $10 \%$ FBS supplemented with $0.5 \mu \mathrm{M}$ dexamethasone, $5 \mu \mathrm{g} / \mathrm{ml}$ insulin, $0.2 \mathrm{~mm}$ indomethacin, and $0.45 \mathrm{~mm}$ isobutylmethylxantine (Sigma-Aldrich, St. Louis, MO, USA). After 24-h FasL and/or neutralizing anti-Fas antibody was added to the cultures. $A D$ medium and treatments were changed twice a week until the end of the experiment. BM-MSCs cultured in complete $\alpha$-MEM without adipogenic supplements were used as control. Alternatively, $24 \mathrm{~h}$ after seeding $25 \mathrm{ng} / \mathrm{ml}$ FasL was added to $\alpha$-MEM for 2 days; floating apoptotic cells were then removed and the medium replaced with $A D$ supplemented with $25 \mathrm{ng} / \mathrm{ml}$ FasL, with or without ZB4 anti-Fas antibody, for 14 days.

Adipocyte staining. Adipocyte differentiation was assessed by Oil Red 0 staining. Briefly, cells were washed with phosphate-buffered saline (PBS), fixed with $4 \%$ paraformaldehyde for $5 \mathrm{~min}$ and incubated for at least $20 \mathrm{~min}$ at room temperature in freshly diluted and filtered Oil Red $\mathrm{O}$ solution (six parts Oil Red $\mathrm{O}$ stock solution and four parts $\mathrm{H}_{2} \mathrm{O}$; Oil Red $\mathrm{O}$ stock solution is $0.5 \%$ Oil Red $\mathrm{O}$ in isopropanol). Cells were also stained with methylene blue $(0.5 \%$ in water) to visualize all cells. The percentage of differentiated cells per treatment was evaluated by counting cells showing lipid droplet accumulation (red) out of the total cell number by light microscopy ( $\times 10$ magnification). At least 20 random fields/ treatment were examined.

Reagents. SuperFasLigand and the pan caspase inhibitor ZVAD $(20 \mu \mathrm{M})$ were purchased from Enzo Life Sciences (Farmingdale, NY, USA). Anti-Fas human activating clone $\mathrm{CH} 11$ and neutralizing anti-Fas antibody ZB4 were purchased from Millipore (Billerica, MA, USA). EGF was obtained from Upstate (Lake Placid, NY, USA) and FGF from Peprotech (Rocky Hill, NJ, USA).

Proliferation assays. For the growth curve study, BM-MSCs were plated at a density of $5 \times 10^{3}$ cells $/ \mathrm{cm}^{2}$ in six-well plates in complete $\alpha$-MEM and treated with different doses of FasL (from 0.1 to $5 \mathrm{ng} / \mathrm{ml}$ ) and/or of neutralizing anti-Fas antibody $(500 \mathrm{ng} / \mathrm{ml})$. Positive controls were BM-MSCs treated with FGF $(5 \mathrm{ng} / \mathrm{ml})$ or EFG $(50 \mathrm{ng} / \mathrm{ml})$. The media were replaced every 2 days until the end of the culture, or twice a week in the case of longer treatments. On days 2, 4, 6, and 14 cells were detached and counted using a hemocytometer. For the BrDU assay, DNA Cell proliferation ELISA BrdU (colorimetric) was purchased from Roche Diagnostics (Mannheim, Germany). Cells were plated in triplicate at $5 \times 10^{3} \mathrm{cells} / \mathrm{cm}^{2}$ in 96-well plates, and treated with FasL alone or with FasL and neutralizing anti-Fas antibody. BrdU labeling solution was added on day 5; plates were read after $24 \mathrm{~h}$ incubation according to the manufacturer's instructions (day 6).

Apoptosis evaluation. Cells were plated at $5 \times 10^{3}$ cells $/ \mathrm{cm}^{2}$ on chamber slides (BD, Franklin Lakes, NJ, USA). Attached cells were treated for 1, 2, 4, or 6 days with FasL alone or with human activating $\mathrm{CH} 11$ anti-Fas antibody (2 days). The latter was used for a comparative study. Cells were then washed twice with PBS, fixed with 4\% paraformaldehyde for 5 min, and stained with Hoechst 33342 (Molecular Probes, Eugene, OR, USA) for $20 \mathrm{~min}$. The percentage of cells with pycnotic nuclei was counted using a fluorescence microscope (Nikon Eclipse 80i, Nikon, Japan) with EX 330-380 and BA 420 filter. At least 10 random fields per treatment were captured and analyzed.

FACS analysis. Cells were treated with 0.5 or $25 \mathrm{ng} / \mathrm{ml}$ FasL for 1 or 6 days or left untreated, and the membrane expression of CD105 (DiaClone, Gen-Probe, San Diego, CA, USA) CD73 (BD), CD90 (Stem Cell Technologies, Vancouver, Canada) and CD44 (Miltenyi Biotech, Cologne, Germany) was assessed by cytofluorimetric analysis (FACScan cytometer, BD). IgG1-PE and IgG2a-FITC (DiaClone) were used as negative controls. 
Protein extraction and immunoblotting. Cells were washed twice in cold PBS. Total protein was extracted using RIPA buffer $(150 \mathrm{~mm} \mathrm{NaCl}, 10 \mathrm{~mm}$ Tris, pH 7.2, $0.1 \%$ SDS, $1.0 \%$ Triton X-100, $5 \mathrm{~mm}$ EDTA, pH 8.0) containing protease inhibitor cocktail (Roche Applied Science, Indianapolis, IN, USA). Protein concentration was determined using Bradford Reagent (Sigma-Aldrich, Milano, Italy). Total protein extracts $(40 \mu \mathrm{g})$ were separated by $10 \%$ SDS-PAGE and transferred to PVDF membranes (Bio-Rad, Hercules, CA, USA). Membranes were blocked with $5 \%$ nonfat dry milk and incubated overnight with anti-survivin (Novus Biologicals, Littleton, CO, USA), mouse anti-caspase 3 (\#9668), anti-caspase 8, rabbit polyclonal anti-caspase 3 (\#9662) (all from Cell Signaling, Danvers, MA, USA), and $\beta$-actin (Santa Cruz Biotechnology, Santa Cruz, CA, USA) primary antibodies. Immunoreactive proteins were visualized using Millipore's Luminata Forte.

For mitogen-activated protein kinase (ERK) phosphorylation assays, cells were starved for $24 \mathrm{~h}$ before treatment with $0.5 \mathrm{ng} / \mathrm{ml}$ superFasL. Protein was extracted with RIPA buffer containing sodium orthovanadate $(1.8 \mathrm{mg} / \mathrm{ml})$. Anti-phospho-ERK and anti-total ERK antibodies were from Cell Signaling and Upstate, respectively. Quantification was performed with Bio-Rad's Quantity-One imaging software, and protein expression calculated as a percentage of the loading control.

Fas ${ }^{\mathrm{Ipr}}$ mice and mRNA and protein extraction. B6.MRL-Fas ${ }^{\mathrm{pr} / \mathrm{J}}$ and C57BL/6J mice (used as control) were purchased from Jackson laboratories (Frederick, MD, USA). They were housed 2-5 per cage in a temperature- and humidity-controlled vivarium with ad libitum water and food, and maintained on a $12 \mathrm{~h}$ light/dark cycle. Animal treatment complied with the National Institutes of Health Guide for the Care and Use of Laboratory Animals, and was approved by the Institutional Animal Care and Use Committees.

Ten-week-old mice were euthanized in a $\mathrm{CO}_{2}$ chamber; both tibias were removed, dissected free of surrounding soft tissue, weighed and immediately frozen. One tibia was used for protein extraction, the other for mRNA extraction. Tibias were homogenized using Precellys 24 homogenizer (Bertin Technologies, Montigny le Bretonneux, France) in MK28-R tubes $(2 \times 20$ s at 5600 r.p.m.) using (i) RIPA buffer, mini complete protease inhibitors, and $0.01 \%$ Triton X-100 for protein preparation, and (ii) Qiagen RNAeasy Plus Universal Mini Kit lysis buffer solution (Qiagen, Düsseldorf, Germany) following the manufacturer's instructions for mRNA extraction. Protein concentration was measured with the BCA method (Pierce, Thermo Scientific, Rockford, IL, USA): equal amounts of protein $(5 \mathrm{mg})$ dissolved in Laemmli loading buffer were loaded in 12 well 4-12\% SDS-PAGE precast minigel (Novex, Life Technologies). Proteins were transferred to Invitrolon PVDF membranes (Life Technologies) and hybridized with PPAR $(\mathrm{C} 26 \mathrm{H} 12)$, FABP4 (D25B3) and GAPDH (D16H11) antibodies (Cell Signaling). Appropriate secondary HRP-conjugated antibodies were used for chemiluminescence detection (Pierce ECL plus, Thermo Scientific). Images were recorded on CCD (Syngene GeneGnome, Frederick, MD, USA) at 30 s intervals. Densitometric analysis of western blot bands was performed using ImageJ software $(\mathrm{NIH})$. Different exposures were used for GAPDH, PPAR $\gamma$, and FABP4 bands.

qRT-PCR. Total RNA was extracted using RNAeasy Extraction Kit (Qiagen). Sample amount was determined by spectrophotometric quantification with Nanodrop ND-1000 (NanoDrop Technologies, Wilmington, DE, USA). Then, $500 \mathrm{pg}$ RNA was reverse transcribed with QuantiTect Reverse Transcription Kit (Qiagen). qRT-PCR was performed in a Chromo 4 PTC-200 Peltier Therma Cycler (MJ Research, Waltham, MA, USA) using 2X SsoFast EvaGreen SuperMix (Bio-Rad) according to the manufacturer's protocol in a $10 \mu \mathrm{l}$ reaction volume. Cycling conditions were: $95^{\circ} \mathrm{C}$ for $30 \mathrm{~s}$, and $95^{\circ} \mathrm{C}$ for $10 \mathrm{~s}, 60^{\circ} \mathrm{C}$ for $30 \mathrm{~s}$, and $72^{\circ} \mathrm{C}$ for $30 \mathrm{~s}$ (40 cycles). Data were analyzed with Real Time PCR Opticon Monitor version 2 (MJ Research). Samples were run in duplicate. Actin was used as an endogenous control.

Primer sequences for human actin, Rex-1, Nanog, Oct-4, CD44, and PPAR were Actin FW: 5'-AAACTGGAACGGTGAAGGTG-3' Actin RV: 5'-CAAGG GACTTCCTGTAACAATGC-3'; CD44st FW: 5'-ATCACCGACAGCACAGACAG-3' CD44st RV: 5'-GGTTGTGTTTGCTCCACCTT-3'; PPAR $\gamma$ FW: 5'-AGCCTCAT GAAGAGCCTTCCA-3' PPAR $\gamma$ RV: 5'-ACCCTTGCATCCTTCACAAGC-3'; Oct-4 FW: 5'-AGTGAGAGGCAACCTGGAGA-3' Oct-4 RV: 5'-ACACTCGGACCA CATCCTTC-3'; Nanog FW: 5'-GATTTGTGGGCCTGAAGAAA-3' Nanog RV: 5'-AAGTGGGTTGTTTGCCTTTG;-3' Rex-1 FW: 5'-AAGGCACTGAACGAGGA GAA-3'; Rex-1 RV: 5'-CTGAGCGAGAAGCTGGTCTT-3'). All primers were purchased from Invitrogen Life Technologies; primers for adiponectin and aP2 were kindly provided by Dr. A Poloni. ${ }^{47}$

Primers for mouse PPAR $\gamma$, FABP4/aP2, RUNX2 and GAPDH were: PPAR FW: 5'-GCCCTTTGGTGACTTTATGG-3', PPAR $\gamma$ RV: 5'-CTCGATGGGCTTCACG
TT-3'; FABP4/aP2 FW: 5'-TCACCTGGAAGACAGCTCCT-3', GAPDH RV: 5'-AAGCCCACTCCCACTTCTTT-3'; RUNX2 FW: 5'-GATGACACTGCCACCTC TGA-3', RUNX2 RV: 5'-ATGAAATGCTTGGGAACTGC-3'; GAPDH FW: 5'-TGC GACTTCAACAGCAACTC-3', GAPDH RV: 5'-ATGTAGGCCATGAGGTCCAC-3'.

Statistical analysis. Data analysis was performed using the SPSS/Win program version 18 (Spss, Chicago, IL, USA). Mean values were compared by a two-tailed $t$-test. The level of statistical significance was defined by a two-tailed $P$-value. $P<0.05$ was considered significant.

\section{Conflict of Interest}

The authors declare no conflict of interest.

Acknowledgements. We are grateful to MC Albertini (University of Urbino, Urbino, Italy) for her critical reading of the manuscript; to L Tessarollo (Neural Development Section, Mouse Cancer Genetics Program, the National Cancer Institute, Frederick, Maryland) for generously making available lab resources for our mice experiments, and to S Modena for language editing (www.silviamodena.com). This work was supported by grants from the Italian Ministry of University and Research to MRR (prot. 2004058593_003) and from Università Politecnica delle Marche to MRR and ADP.

1. Méndez-Ferrer S, Michurina T, Ferraro F, Mazloom A, Macarthur B, Lira $S$ et al. Mesenchymal and haematopoietic stem cells form a unique bone marrow niche. Nature 2010; 466: 829-834.

2. Fox J, Chamberlain G, Ashton B, Middleton J. Recent advances into the understanding of mesenchymal stem cell trafficking. Br J Haematol 2007; 137: 491-502.

3. Kawai M, Sousa K, MacDougald O, Rosen C. The many facets of PPARgamma: novel insights for the skeleton. Am J Physiol Endocrinol Metab 2010; 299: E3-E9.

4. Tsutsumi S, Shimazu A, Miyazaki K, Pan H, Koike C, Yoshida E et al. Retention of multilineage differentiation potential of mesenchymal cells during proliferation in response to FGF. Biochem Biophys Res Commun 2001; 288: 413-419.

5. Krampera M, Pasini A, Rigo A, Scupoli M, Tecchio C, Malpeli G et al. HB-EGF/HER-1 signaling in bone marrow mesenchymal stem cells: inducing cell expansion and reversibly preventing multilineage differentiation. Blood 2005; 106: 59-66.

6. Pricola K, Kuhn N, Haleem-Smith H, Song Y, Tuan R. Interleukin-6 maintains bone marrow-derived mesenchymal stem cell stemness by an ERK1/2-dependent mechanism. J Cell Biochem 2009; 108: 577-588.

7. Muruganandan S, Roman A, Sinal C. Adipocyte differentiation of bone marrow-derived mesenchymal stem cells: cross talk with the osteoblastogenic program. Cell Mol. Life Sci 2009; 66: 236-253

8. Song L, Webb N, Song Y, Tuan R. Identification and functional analysis of candidate genes regulating mesenchymal stem cell self-renewal and multipotency. Stem Cells 2006; 24: $1707-1718$

9. Zieleniak A, Wójcik M, Woźniak L. Structure and physiological functions of the human peroxisome proliferator-activated receptor $\gamma$. Arch Immunol Ther Exp 2008; 56: 331-335.

10. Rosen E, Spiegelman B. PPARgamma: a nuclear regulator of metabolism, differentiation, and cell growth. J Biol Chem 2001; 276: 37731-37734.

11. Artemenko Y, Gagnon A, Aubin D, Sorisky A. Anti-adipogenic effect of PDGF is reversed by PKC inhibition. J Cell Physiol 2005; 204: 646-653.

12. Lecka-Czernik B. Marrow fat metabolism is linked to the systemic energy metabolism. Bone 2012; 50: 534-539.

13. Dragojevi J, Logar D, Komadina R, Marc J. Osteoblastogenesis and adipogenesis are higher in osteoarthritic than in osteoporotic bone tissue. Arch Med Res 2011; 42 392-e397.

14. Huang J, Mulkern R, Grinspoon S. Reduced intravertebral bone marrow fat in HIV-infected men. AIDS 2002; 16: 1265-1269

15. Rosen C, Bouxsein M. Mechanisms of disease: is osteoporosis the obesity of bone? Nat Clin Pract Rheum 2006; 2: 35-43.

16. Suda T, Takahashi T, Goldstein P, Nagata S. Molecular cloning and expression of the Fas ligand, a novel member of the tumor necrosis factor family. Cell Death Differ 1993; 75 : 1169-1178.

17. Strasser $A$, Jost $P$, Nagata $S$. The many roles of $F A S$ receptor signaling in the immune system. Immunity 2009; 30: 80-92.

18. Paulsen M, Valentin S, Mathew B, Adam-Klages S, Bertsch U, Lavrik I et al. Modulation of CD4 + T-cell activation by CD95 co-stimulation. Cell Death Differ 2011; 18: 619-631.

19. Pearl-Yafe M, Stein J, Yolcu E, Farkas D, Shirwan H, Yaniv I et al. Fas transduces dual apoptotic and trophic signals in hematopoietic progenitors. Stem Cells 2007; 25: 3194-3203.

20. O'Reilly L, Tai L, Lee L, Kruse E, Grabow S, Fairlie W et al. Membrane-bound Fas ligand only is essential for Fas-induced apoptosis. Nature 2009; 461: 659-663. 
21. Li H, Cai X, Fan X, Moquin B, Stoicov C, Houghton J. Fas Ag-FasL coupling leads to ERK1/ 2-mediated proliferation of gastric mucosal cells. Am J Physiol Gastrointest Liver Physiol 2008; 294: G263-G275.

22. Poonia B, Pauza C, Salvato M. Role of the Fas/FasL pathway in HIV or SIV disease. Retrovirology 2009; 6: 91.

23. Hosaka N, Oyaizu N, Kaplan M, Yagita H, Pahwa S. Membrane and soluble forms of Fas (CD95) and Fas ligand in peripheral blood mononuclear cells and in plasma from human immunodeficiency virus-infected persons. $J$ Infect Dis 1998; 178: 1030-1039.

24. Shimizu M, Fukuo K, Nagata S, Suhara T, Okuro M, Fujii K et al. Increased plasma levels of the soluble form of Fas ligand in patients with acute myocardial infarction and unstable angina pectoris. J Am Coll Cardiol 2002; 39: 585-590.

25. Wang C, Zhong W, Chang T, Tsai Y. Circulating soluble Fas ligand correlates with disease activity in Graves' hyperthyroidism. Metabolism 2002; 51: 769-673.

26. Lettau M, Paulsen M, Schmidt $H$, Janssen O. Insights into the molecular regulation of FasL (CD178) biology. Eur J Cell Biol 2011; 90: 456-466.

27. Kirkin V, Cahuzac N, Guardiola-Serrano F, Huault S, Lückerath K, Friedmann E et al. The Fas ligand intracellular domain is released by ADAM10 and SPPL2a cleavage in T-cells. Cell Death Differ 2007; 14: 1678-1687.

28. Kovacić N, Lukić I, Grcević D, Katavić V, Croucher P, Marusić A. The Fas/Fas ligand system inhibits differentiation of murine osteoblasts but has a limited role in osteoblast and osteoclast apoptosis. J Immunol 2007; 178: 3379-3389.

29. Mazar J, Thomas M, Bezrukov L, Chanturia A, Pekkurnaz G, Yin S et al. Cytotoxicity mediated by the Fas ligand (FasL)-activated apoptotic pathway in stem cells. $J$ Biol Chem 2009; 284: 22022-22028.

30. Kennea N, Stratou C, Naparus A, Fisk N, Mehmet H. Functional intrinsic and extrinsic apoptotic pathways in human fetal mesenchymal stem cells. Cell Death Differ 2005; 12 : 1439-1441.

31. Rodrigues M, Turner O, Stolz D, Griffith L, Wells A. Production of reactive oxygen species by multipotent stromal cells/mesenchymal stem cells upon exposure to Fas Ligand. Cell Transplant 2012; 21: 2171-2187.

32. Rippo M, Villanova F, Ardori FT, Graciotti L, Amatori S, Manzotti S et al. Dexamethasone affects Fas- and serum deprivation-induced cell death of human osteoblastic cells through survivin regulation. Int J Immunopathol Pharmacol 2010; 23: 1153-1165.

33. Rojewski M, Weber B, Schrezenmeier H. Phenotypic characterization of mesenchymal stem cells from various tissues. Transfus Med Hemother 2008; 35: 168-184.

34. Desbarats J, Birge R, Mimouni-Rongy M, Weinstein D, Palerme J, Newell M. Fas engagement induces neurite growth through ERK activation and $\mathrm{p} 35$ upregulation. Nat Cell Biol 2003; 5: 118-125.
35. Fukuda S, Foster R, Porter S, Pelus L. The antiapoptosis protein survivin is associated with cell cycle entry of normal cord blood CD34 $(+)$ cells and modulates cell cycle and proliferation of mouse hematopoietic progenitor cells. Blood 2002; 100: 2463-2471.

36. Solmesky L, Lefler S, Jacob-Hirsch J, Bulvik S, Rechavi G, Weil M. Serum free cultured bone marrow mesenchymal stem cells as a platform to characterize the effects of specific molecules. PLoS One 2010; 5, pii e12689.

37. Altieri D. Survivin and IAP proteins in cell death mechanisms. Biochem J 2010; 430: 199-205.

38. Uren A, Wong L, Pakusch M, Fowler K, Burrows F, Vaux D et al. Survivin and the inner centromere protein INCENP show similar cell- cycle localization and gene knockout phenotype. Curr Biol 2000; 10: 1319-1328.

39. Gurbuxani $S, X u Y$, Keerthivasan G, Wickrema A, Crispino J. Differential requirements for survivin in hematopoietic cell development. Proc. Natl Acad Sci USA 2005; 102: 11480-11485.

40. Kavathia N, Jain A, Walston J, Beamer B, Fedarko N. Serum markers of apoptosis decrease with age and cancer stage. Aging 2009; 1: 652-663.

41. Torti F, Dieckmann B, Beutler B, Cerami A, Ringold G. A macrophage factor inhibits adipocyte gene expression: an in vitro model of cachexia. Science 1985; 229: 867-869.

42. Naveiras $\mathrm{O}$, Nardi V, Wenzel P, Fahey F, Daley G. Bone marrow adipocytes as negative regulators of the hematopoietic microenvironment. Nature 2009; 460: 259-263.

43. Brazil J, Gupta P. Constitutive expression of the fas receptor and its ligand in adult human bone marrow: a regulatory feedback loop for the homeostatic control of hematopoiesis. Blood Cells Mol Dis 2002; 29: 94-103.

44. Mulkern R, Huang J, Vajapeyam S, Packard A, Oshio K, Grinspoon S. Fat fractions and spectral T2 values in vertebral bone marrow in HIV- and non-HIV-infected men: a $1 \mathrm{H}$ spectroscopic imaging study. Magn Reson Med 2004; 52: 552-528.

45. Pinti M, Troiano L, Nasi M, Bellodi C, Ferraresi R, Mussi C et al. Balanced regulation of mRNA production for Fas and Fas ligand in lymphocytes from centenarians: how the immune system starts its second century. Circulation 2004; 110: 3108-3114.

46. Duque G. Bone and fat connection in aging bone. Curr Opin Rheumatol 2008; 20: 429-434.

47. Poloni A, Maurizi G, Leoni P, Serrani F, Mancini S, Frontini A et al. Human dedifferentiated adipocytes show similar properties to bone marrow-derived mesenchymal stem cells. Stem Cells 2012; 30: 965-974.

(1) (2) (2) Cell Death and Disease is an open-access journal (c) licensed under a Creative Commons Attribution-NonCommercialShareAlike 3.0 Unported License. To view a copy of this license, visit http://creativecommons.org/licenses/by-nc-sa/3.0/

\section{Supplementary Information accompanies this paper on Cell Death and Disease website (http://www.nature.com/cddis)}

